\title{
Wave power conversion systems for electrical energy production
}

\author{
Leão Rodrigues \\ Department of Electrical Engineering \\ Faculty of Science and Technology \\ Nova University of Lisbon \\ 2829-516 Caparica - PORTUGAL \\ e-mail: leao@uninova.pt Teleph: +351 212948545
}

\begin{abstract}
Due to economic social cohesion, the European Union is promoting to improve the production of electrical energy from renewable energy sources. Sea waves have associated a form of renewable energy which can be captured by using a hydro mechanical device that in turn drives an electrical generator to produce electrical energy.

After a brief description of wave formation and quantifying the power across each meter of wave front associated to the wave, the paper describes several devices used presently to extract mechanical energy from the waves and their advantages and disadvantages are presented as conclusions. In particular, the modern Pelamis system is described in some detail.

Wave energy market is also discussed.
\end{abstract}

\section{Key words}

Wave Power; Devices to convert wave energy; Pelamis wave energy converter; Wave energy market.

\section{Introduction}

Wave power refers to the energy of ocean surface waves and the capture of that energy to do useful work. Sea waves are a very promising energy carrier among renewable power sources, since they are able to manifest an enormous amount of energy resources in almost all geographical regions. The global theoretical energy from waves corresponds to $8 \times 10^{6} \mathrm{TWh} /$ year, which is about 100 times the total hydroelectricity generation of the whole planet. To produce this energy using fossil fuels it would result an emission of 2 millions of tones of $\mathrm{CO}_{2}$. This means that wave energy could contribute heavily for the attenuation of pollutant gases in the atmosphere, as defended by the Kyoto Protocol.

The global wave resource due to wave energy is roughly 2 TW and Europe represents about $320 \mathrm{GW}$, which is about $16 \%$ of the total resource. However, for various reasons, it is estimated that only 10 to $15 \%$ can be converted into electrical energy, which is a vast source of energy, able to feed the present all world.

Eventually, wave energy could make a major contribution by yielding as much as $120 \mathrm{TWh} /$ year for Europe and perhaps three times that level worldwide. The ocean is a true store of renewable energy.

\section{Sea Waves Formation}

The combination of forces due to the gravity, sea surface tension and wind intensity are the main factors of origin of sea waves. Figure 1 illustrates the formation of sea waves by a storm. Wave size is determined by wind speed and fetch (the distance over which the wind excites the waves) and by the depth and topography of the seabed (which can focus or disperse the energy of the waves). To distances far from the fetch, sea waves have a regular shape and the phenomenon is called swell

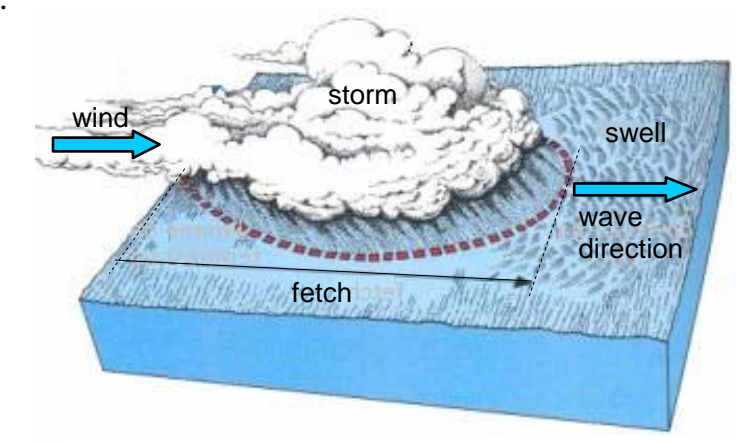

Fig. 1. Sea waves formation due to a storm

The water particles excited by the wind have in each location of the ocean circular trajectories with highest diameter at the surface and diminishing exponentially with depth. The conjugation of this circular motion is responsible for the wave formation and respective propagation, as shown in figure 2.

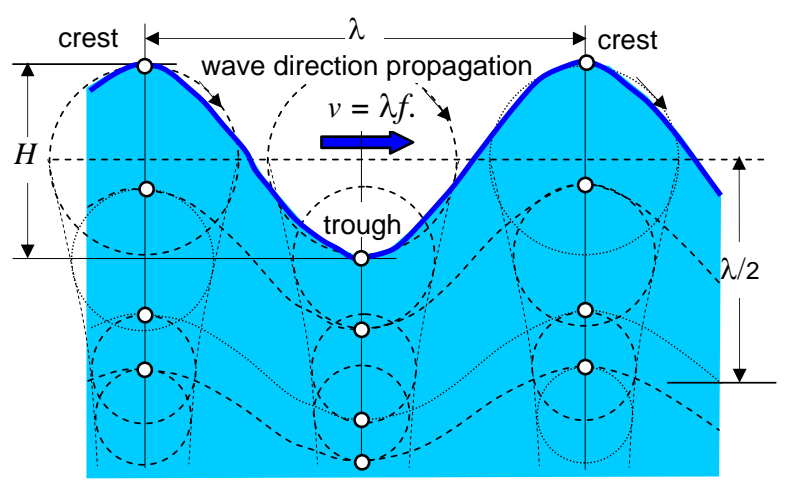

Fig. 2. Propagation of sea waves 
The distance between two consecutive crests, or two consecutive troughs, defines the wavelength $\lambda$. Wave height $H$ (crest to trough) is proportional to wind intensity and its duration.

The wave period $T$ (crest to crest) is the time in seconds needed for the wave travelers the wavelength $\lambda$ and is proportional to sea depth. The frequency $f=1 / T$ indicates the number of waves that appears in a given position. Consequently the wave speed is $v=\lambda / T=\lambda / f$. The ratio $\lambda / 2 \mathrm{H}$ is called the wave declivity and when this value is greater than $1 / 7$ can be proved that the wave becomes unstable and vanishes.

Longer period waves have relatively longer wavelengths and move faster. Generally, large waves are more powerful.

\section{Power Associated to a Sea Wave}

Ocean waves transport mechanical energy. The power associated with a wave of wavelength $\lambda$ and height $H$ and a front $b$ is given by

$$
P=\frac{1}{2} \rho g H^{2} \lambda b
$$

where $\rho$ is the water specific weight and $g$ is the gravity acceleration. The power across each meter of wave front associated to an uniform wave with height $H(\mathrm{~m})$ and wavelength $\lambda(\mathrm{m})$ is then

$$
P_{u}=\frac{P}{b}=\frac{1}{2} \rho g H^{2} \lambda
$$

and is expressed in $\mathrm{W} / \mathrm{m}$.

During a "tsunami", waves far from the beach have long wavelength $\lambda_{1}$ a small height $H_{1}$ but great power. When the waves propagate into the beach the power is kept almost constant (neglecting friction) and the wavelength decreases to $\lambda_{2}$. Therefore, Eq. (2) shows that the height of the wave must increases to square $\mathrm{H}_{2}^{2}$ in order to maintain $P_{\mathrm{u}}$ constant, as illustrated in figure 3 . These big waves have devastated effects on the beach!

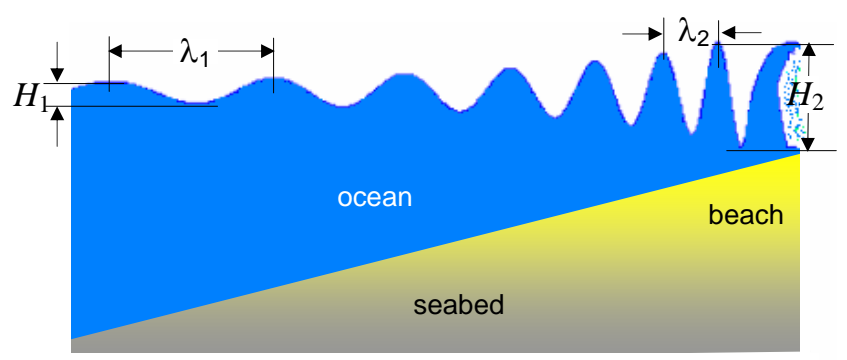

Fig.3 Formation of a "tsunami"

For irregular waves of height $H(\mathrm{~m})$ and period $T$ (s), an equation for power per unit of wave front can be derived as

$$
P_{i} \cong 0.42 H^{2} T
$$

and is expressed in kilowatts per meter $(\mathrm{kW} / \mathrm{m})$ of wave front. It is significant to note that wave power varies with the square of wave height. Then, when wave height is doubled generates four times as much power [1].

Excluding waves created by major storms, the largest waves are about 15 meters high and have a period of about 15 seconds. According to the Eq.(3), such waves carry about 1700 kilowatts of potential power across each meter of wave front. A good wave power location will have an average flux much less than this, perhaps about $50 \mathrm{~kW} / \mathrm{m}$. The Atlantic waves along northwest cost have an average value o $40 \mathrm{~kW} / \mathrm{m}$.

\section{World Resource of Wave Power}

Wave energy is unevenly distributed over the globe. Figure 4 shows an Atlas of the global power density distribution of the oceans where the numbers indicate $\mathrm{kW} / \mathrm{m}$. The north and south temperature zones have the best sites for capturing wave power. The prevailing winds in these zones blow strongest in winter. Increased wave activity is found between the latitudes of $30^{\circ}$ and $60^{\circ}$ on both hemispheres, induced by the prevailing western winds blowing in these regions

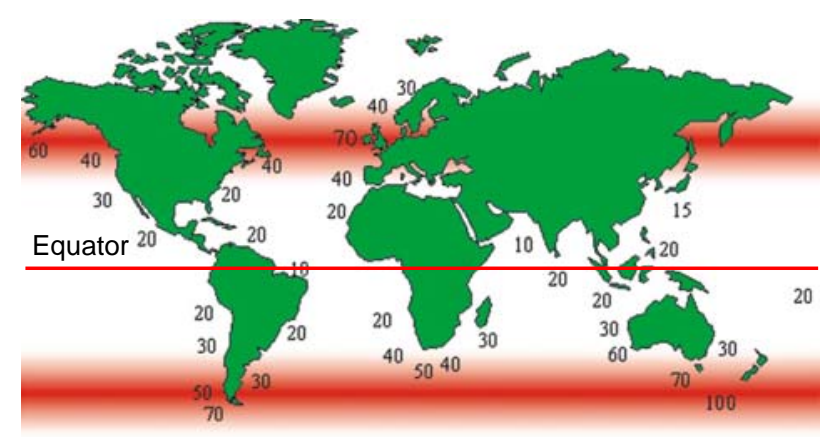

Fig.4 Global wave power distribution in $\mathrm{kW} / \mathrm{m}$

The oceanic wave climate (i.e. far offshore) offers enormous levels of energy. As waves approach the shore, energy is dissipated, leading to lower wave power levels on the shoreline. Therefore, the energy availability is sensitive to location and the distance from the shoreline.

\section{Types of Wave Power Mechanisms}

The sea wave's motion can be converted into mechanical energy by using proper wave power mechanisms. There are currently about 40 types of mechanisms for exploiting the energy available in waves, several of which are now being constructed. These devices are generally categorized by location installed and power take-off system.

Locations are shoreline, nearshore and offshore. Power take-off systems can be oscillating column of water, underwater pneumatic systems, wave dragon system and oscillating bodies system. Also these mechanisms can be lying on the bottom of the sea, on the shoreline and on sea level.

Description of these systems is following presented. 


\section{- Shoreline Locations}

\section{A Oscillating Water Column}

This system consists of a chamber built in shoreline cost with the layout shown in figure 5. The motions of ocean/sea waves push an air pocket up and down behind a breakwater. Then the air passes through an air turbine. Next, when the wave returns to the sea, an air depression will circulate through the turbine in the opposite sense. However, this turbine has been designed to continue turning the same way irrespective of the direction of the airflow.

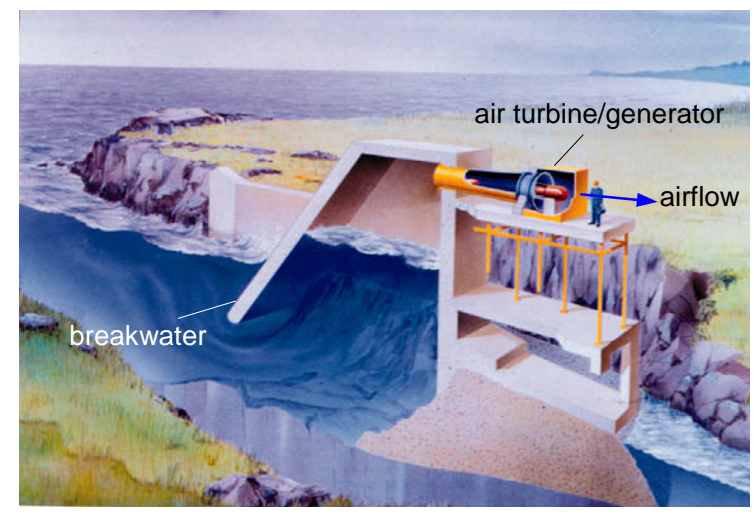

Fig. 5 Oscillating column of water system

This is a rectifier Wells turbine type, designed by Professor Alan Wells of Queen's University, which drives an electric generator mounted on the same shaft, as illustrated in figure 6 . To control the air pressure inside the camera a valve in parallel (sometimes in series) with the turbine is used.

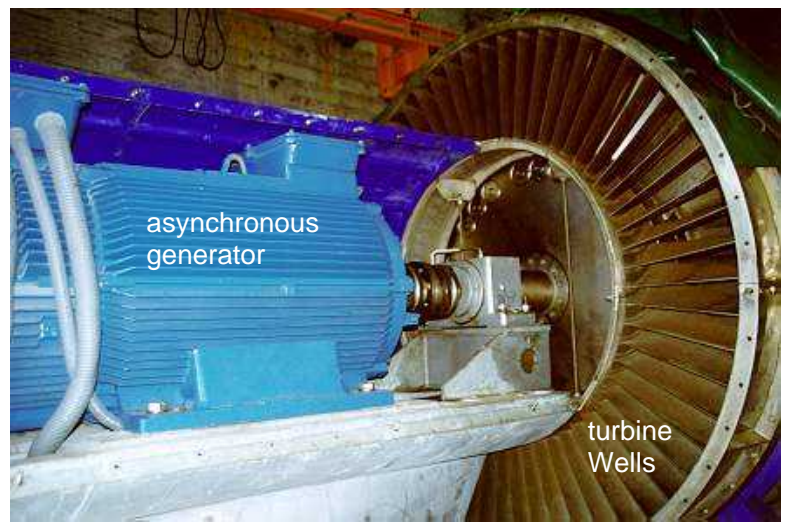

Fig. 6 Generator / rectifier air turbine group

The generator delivers power into the grid with constant frequency and rms voltage. Because the turbine rotates with a variable speed a synchronous machine is not appropriate. Instead, a double fed wound rotor induction generator is used, as shown diagrammatically in figure 7. The wound rotor is fed by the stator using a converter and with this arrangement the frequency and voltage is kept constant for a large range of turbine speed variation.
A prototype of $40 \mathrm{~kW}$ using an asynchronous generator was installed in Pico Island, Azores, Portugal, and an optimal overall efficiency of $35 \%$ was claimed $[2,3,4]$.

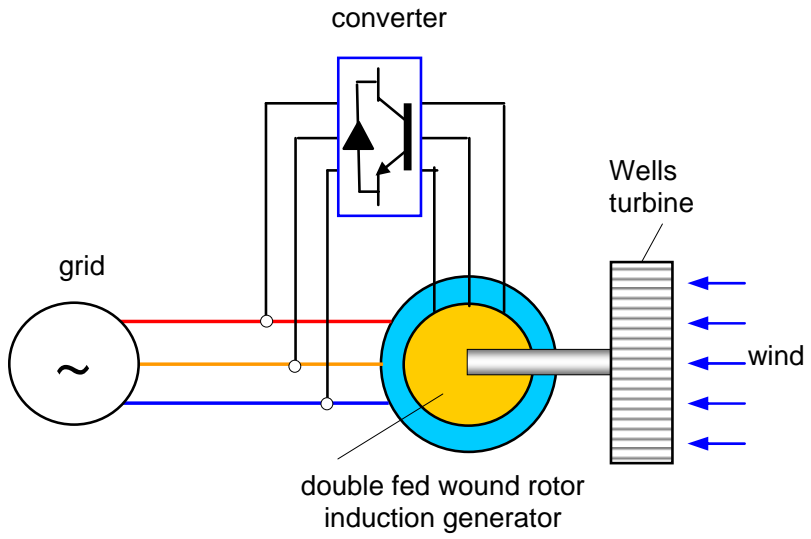

Fig. 7 Wound induction generator variable speed diagram

The problem with this pneumatic system is that the rushing air can be very noisy, unless a silencer is fitted to the turbine. But the noise is not a huge problem anyway, as the waves make quite a bit of noise themselves.

\section{B Pendulum System}

The Pendulum system is also installed in the shoreline and consists of a parallelepiped concrete box, which is open to the sea at one end, as shown in figure 8.

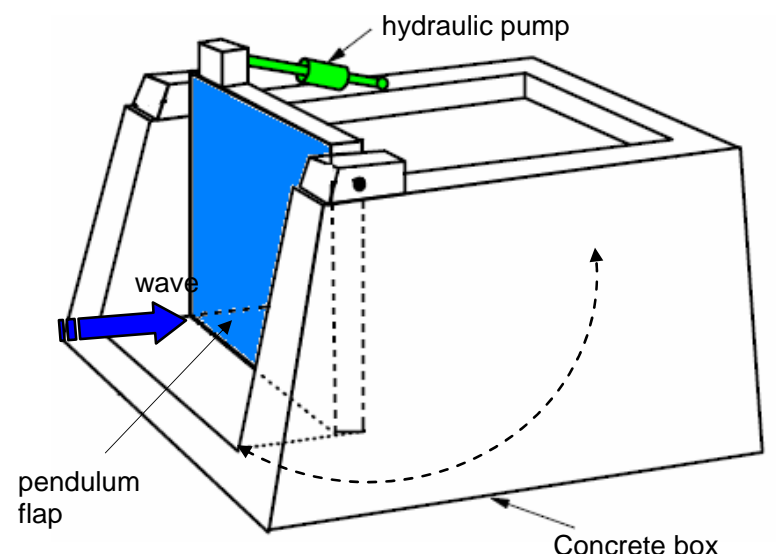

Fig.8 Pendulum system

A pendulum flap is hinged over this opening, so that the actions of the waves cause it to swing back and forth. This motion is then used to power a hydraulic pump and an electric generator.

\section{- Nearshore Locations}

\section{Offshore Wave Dragon System}

Wave Dragon System is a floating slack-moored energy converter of the overtopping type that can be displayed in a single unit or in arrays. Groups of 200 Wave Dragon 
units result in a wave power park with a capacity comparable to a traditional fossil fuel based power plant. The Wave Dragon system was the world's first nearshore wave energy converter producing power for the grid. The basic idea of this system consists of two large "arms" that focus waves up a ramp into a reservoir. The water returns to the ocean by the force of gravity via a low head hydro turbine which drives an electric generator. Figure 9 illustrates this principle

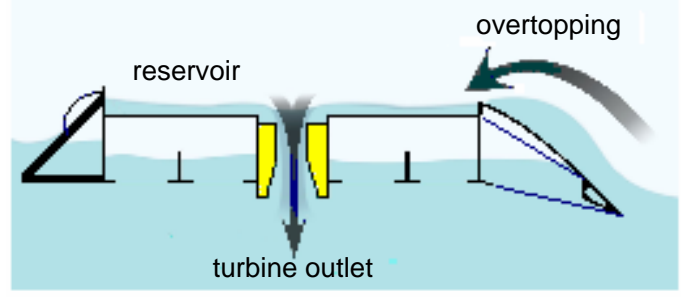

Fig. 9 Wave Dragon System Principle

Wave Dragon is a very simple construction and only the turbines are the moving parts. This is essential for any device bound for operating nearshore where the extreme forces seriously affect any moving parts. In comparison with traditional hydroelectric power stations, this new technology is competitive. Figure 10 shows a photograph of the Wave Dragon system installed nearshore

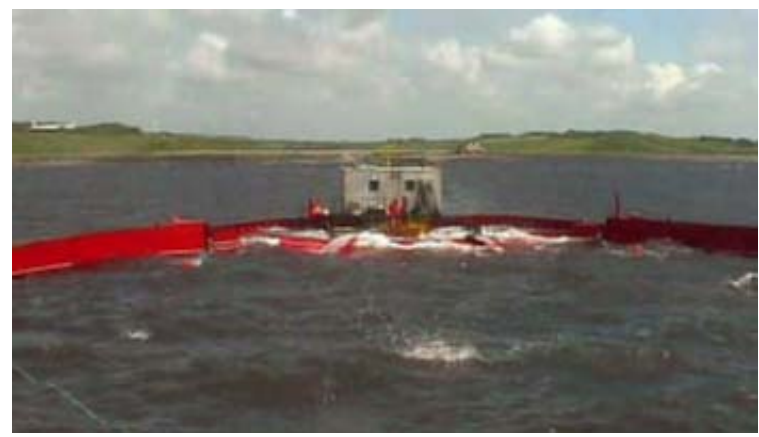

Fig. 10 Wave Dragon System Installation Nearshore

The Wave Dragon concept combines existing, mature nearshore and hydro turbine technology in a novel way. Due to its size service, maintenance and even major repair works can be carried out at sea leading to low cost relative to others systems.

\section{- Offshore Locations}

\section{Power Buoy}

This system utilizes the Power Buoy technology which consists of modular ocean-going buoys, as shown in figure 11.The rising and falling of the waves moves the buoy-like structure creating mechanical energy which is converted into electricity and transmitted to shore by means a secure, undersea transmission line.

A buoy with $40 \mathrm{~kW}$ power has a diameter of $4 \mathrm{~m}$ and is $16 \mathrm{~m}$ long, with approximately $5 \mathrm{~m}$ of the unit rising
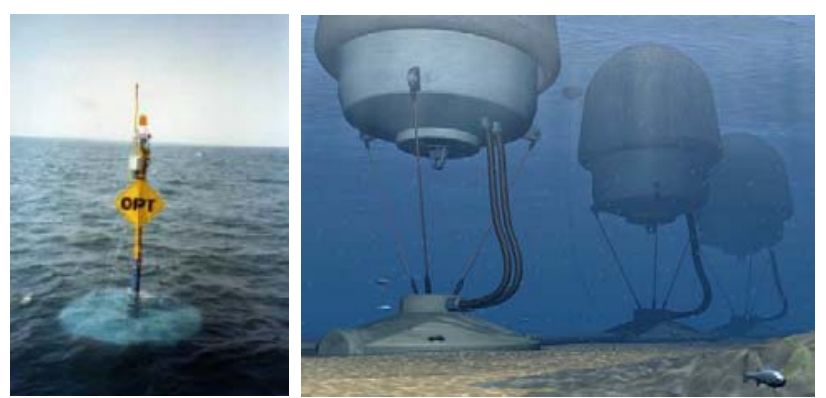

Fig. 11 Power Buoy

above the ocean surface. Using the three-point mooring system, they are designed to be installed about $8 \mathrm{~km}$ offshore in water 40 to $60 \mathrm{~m}$ deep.

\section{E Salter's Duck System}

One of the first methods to extract mechanical energy from the waves was invented in the 1970s by Professor Stephen Salter of the University of Edinburgh, Scotland, in response to the Oil Crisis. A cross section of the Salter cam (or Duck) is shown in figure 12 and can be moored, to distances of $80 \mathrm{~km}$ of the cost. The cam rotates about its axis and is shaped to minimize back-water pressures.

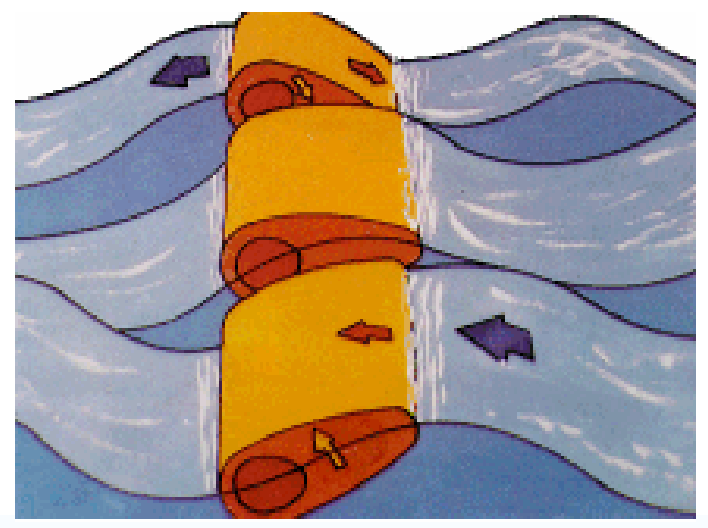

Fig. 12 Salter’s Duck system

Conversion of the float movement into electrical energy is difficult because of the slow oscillations. While it continues to represent the most efficient use of available material and wave resources, the machine has never gone to sea, primarily because its complex hydraulic system is not well suited to incremental implementation, and the costs and risks of a full-scale machine would be high. Most of the prototypes being tested absorb far less of the available wave power, and as a result their mass/power ratio remain far away from the theoretical maximum [5].

\section{F Pelamis Wave Energy Converter}

The Pelamis Wave Energy Converter, a Scottish invention, consists of six articulated cylinders of $3.5 \mathrm{~m}$ in diameter and $30 \mathrm{~m}$ in length (floaters) articulated connected to four cylinders of $3.5 \mathrm{~m}$ in diameter and $5 \mathrm{~m}$ 
in length (power modules) This articulated structure with $140 \mathrm{~m}$ in a total length is placed 2/3 semi-submerged offshore in deep waters, as shown in figure 13. Due to the waves, this structure up and down and side to side as a sea snake (Pelamis in Greek).

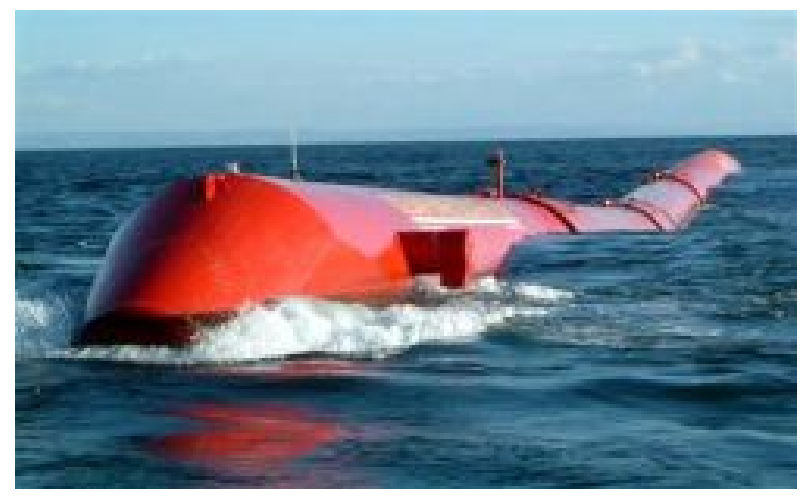

Fig. 13 Pelamis Wave Energy Converter

The structure is secured by flexile cables fitted to the seabed. in such way that the float axis is oriented in the predominant wave direction. Figure 14 shows the Pelamis structure anchored to the seabed.

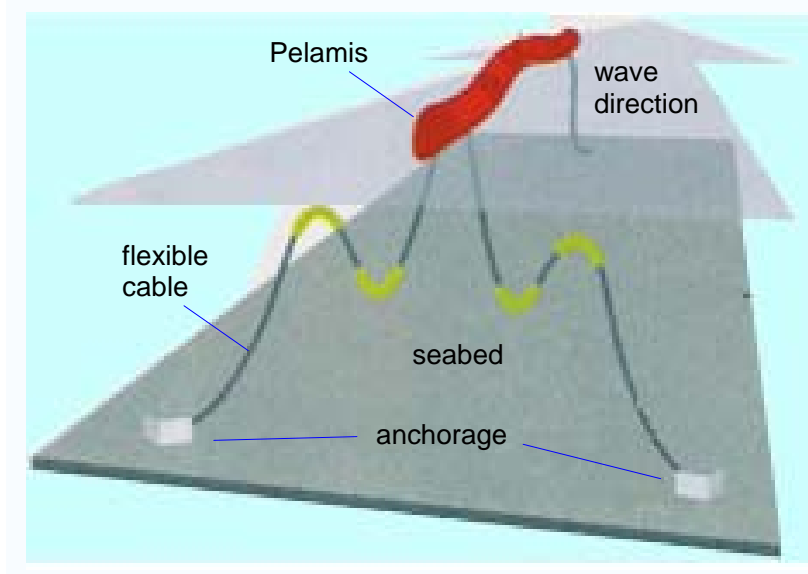

Fig. 14 Pelamis fixation to the seabed

This long, hinged tube as the hinges bend, they pump hydraulic fluid creating pressurized oil to drive a hydraulic motor that drives an electric generator, mounted inside the $5 \mathrm{~m}$ floating power module, as shown in figure 15

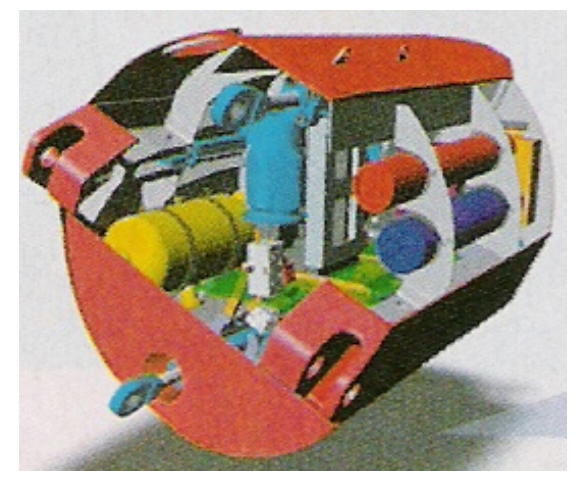

Fig. 15 Inside view of the power module
Each of these four modules has a $250 \mathrm{~kW}$ electric generator giving a total power of $750 \mathrm{~kW}$ for each Pelamis unit. A $10 \mathrm{kV}$ three phase power transformer is situated in the front floater and send the electric energy across underwater power cables to a substation in land. Figure 16 shows an association of various numbers of units constituting a wave farm [6].

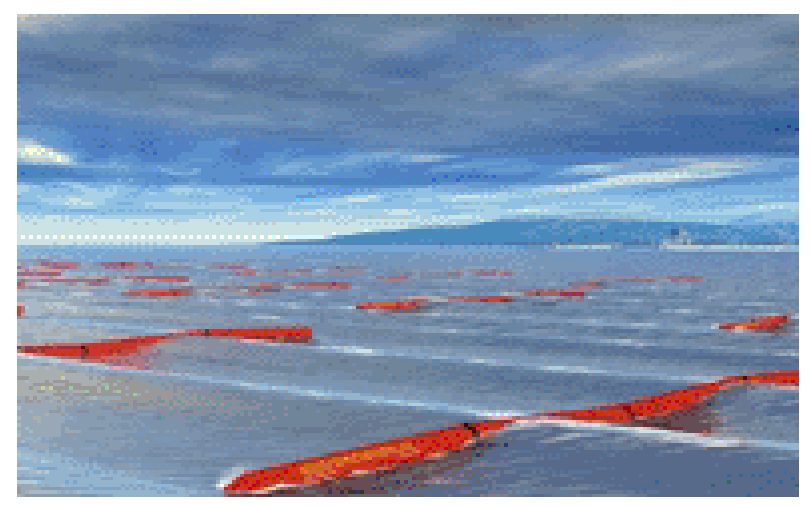

Fig. 16 Pelamis wave farm

A wave farm utilizing Pelamis technology was recently installed in Aguçadora Wave Park, about three miles off Portugal's northern coast, near Póvoa do Varzim, The wave farm initially uses three Pelamis P-750 machines developing a total power of 2.25 MW. Other plans for wave farms include a 3MW array of four $750 \mathrm{~kW}$ Pelamis devices in the Orkneys, off northern Scotland, and the 20MW Wave hub development off the north coast of Cornwall, England.

Only one Pelamis-750 placed on the sea of $55 \mathrm{~kW} / \mathrm{m}$ average intensity will produce per year a total energy of $2,2 \times 10^{6} \mathrm{kWh}$. This gives a load factor $\alpha$ of

$$
\alpha=\frac{2,2 \times 10^{6} \mathrm{kWh}}{750 \mathrm{~kW}(365 \text { dias } \times 24 \text { horas })}=0,34
$$

Usually other devices for extraction wave energy have lower load factors, of the order of 0.25 . This calculation shows that the Pelamis system presents a great advantage for future investments and an amazing breakthrough in power generation. The system is safe, easy to install, and not harmful to the environment, although some legislation has to be published.

\section{H Wave Roller System}

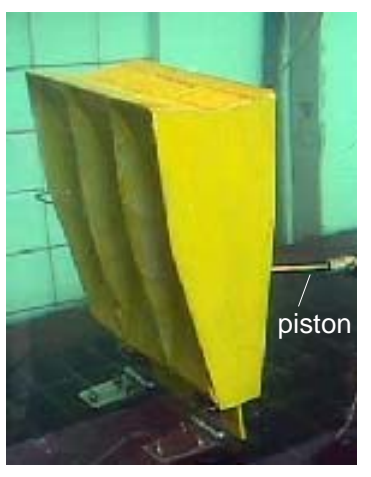

The Wave Roller System is a plate lying on the bottom of the sea, whose back and forth movement caused by bottom waves is collected by a piston, as illustrated in figure 17.

The piston compresses oil to power a hydraulic motor, which drives in turn an electric generator to produce electrical energy.

Fig. 17 Wave Roller plate 
This is a typical undersea system used because the bottom waves are more continuous and predictable than surface waves. Figure 18 shows an array of these floating plates placed on seabed.

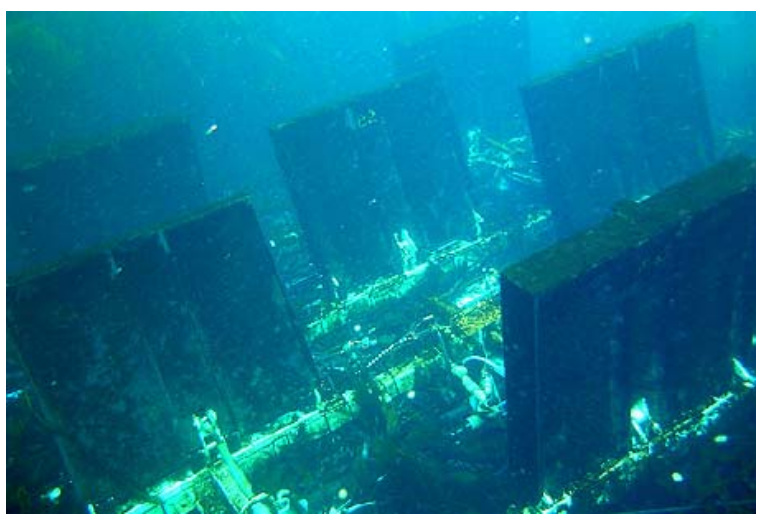

Fig. 18 Array of Wave Roller plates.

Invisible from the surface, the system has a low environmental impact. Unit plates of $15 \mathrm{~kW}$ each are generally used. Contract discussions to install the Wave Roller System are already underway in Finland.

\section{G The Archimedes Wave Swing}

The Archimedes Wave Swing (AWS) is a submerged cylinder shaped buoy, moored to the seabed, at least six metres below the sea surface. Passing waves move an air filled upper casing against a lower fixed cylinder, with the up and down movement converted into mechanical energy, as shown in figure 19.

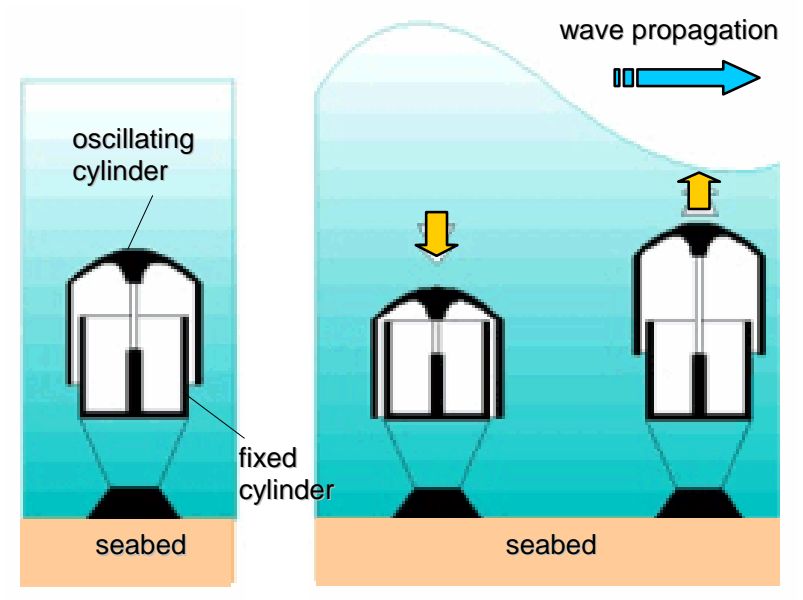

Fig. 19 Archimedes Wave Swing

The mechanical energy is converted into electrical energy by means a linear synchronous generator. The stator is a fixed coil to seabed. The linear rotor is a permanent magnet connected to the oscillating buoy by means a shaft, as illustrated diagrammatically in figure 20. During the rotor oscillation the linked magnetic flux $\psi$ with the coil will induce in it, according to Faraday law, an emf given by

$$
e(t)=-\frac{d \psi}{d t}
$$

giving an alternating voltage at coil terminals, which can be applied to an electric load. Compared to most other wave energy devices, the Archimedes Wave Swing also takes up a proportionately smaller area of the sea, in relation to power generated.

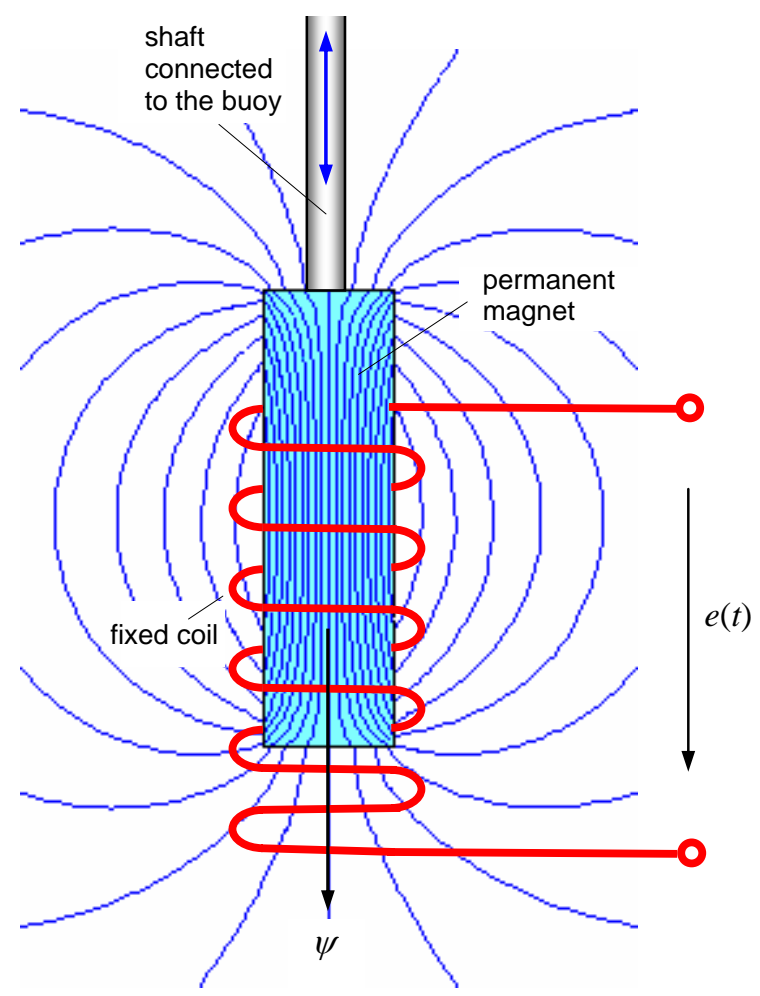

Fig. 20 AWS permanent magnet linear electric generator

With a low environmental impact and hazards to shipping, Archimedes Wave Swing system has high power density, it can survive the most violent storms and minimising maintenance at sea.

It is believed that this system will lead directly to the construction of the first mini wave park of Archimedes units in Scottish waters, by the third quarter of 2010, expanding within 12 months to 20 units.

The main early markets for Archimedes Wave Swing will be Scotland, Portugal and Spain.

\section{H Bristol Cylinder}

The Bristol Cylinder consists in a floating cylinder that collected the wave's movement. The cylinder is mechanically connected to the energy unit by flexible joints and rods. The rods are moving slowly with cylinder and the reciprocating motion is transferred to the axels in converter unit. This converter unit, called Escone, after his inventor Esko Raikano, is the heart of the system and converts the reciprocating motion to a rotating shaft connected direclty to a generator for generating electrical energy with high efficiency. For the energy unit a suitable slow speed generator will be needed. When transfering converter movements with mechanical arms and rotation 
to the generator the efficiency should be kept as high as possible. The Bristol Cylinder operates under the sea level as shown in figure 21.

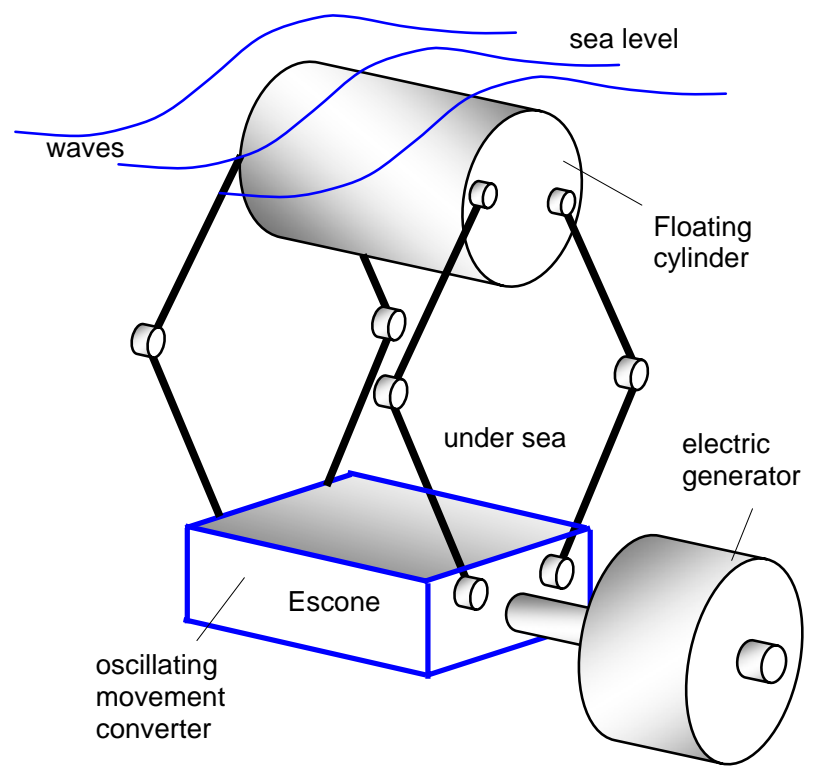

Fig. 21 Bristol cylinder for wave energy extraction

Two or more Bristol cylinders could be connected in parallel. It is also possible to make wave parks near shore or wind power units connected together like float offshore. In offshore the converter parts can be located above the sea level and the collector rotation just under the sea surface. This method of collector wave energy is in the process of pending patents in Finland.

\section{Wave Energy Market}

Construction of wave parks should be made in areas of moderated or lower environment sensibility, using safe technologies. The relative costs distribution of a wave park plant is shown displayed in the graph of figure 22 .

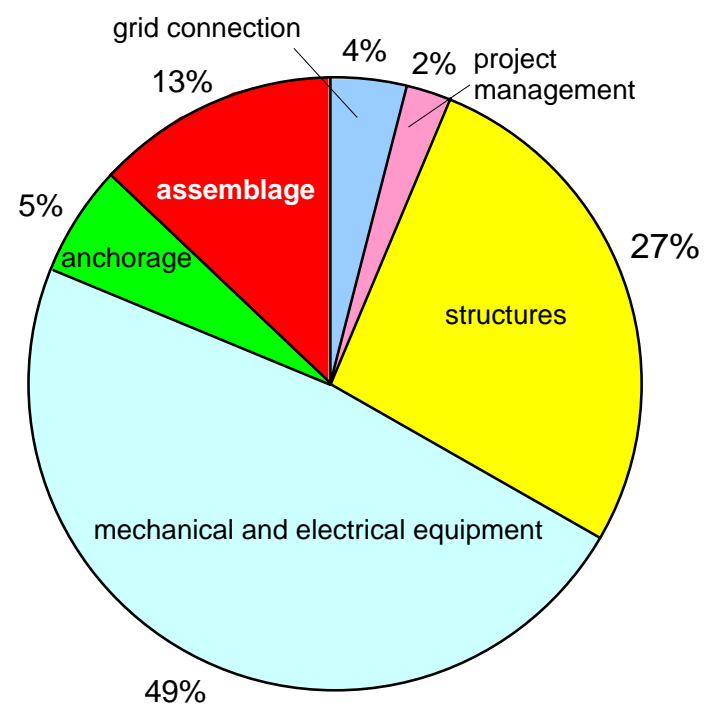

Fig. 22 Costs distribution for a wave power plant
The MW cost installed to be competitive is situated in 0.5 to $0.6 \mathrm{M} € / \mathrm{MW}$ and the economic competitive is attainable when is installed at least a power of $6.8 \mathrm{GW}$. Presently, the world wave energy market is situated in $750 \times 10^{6} €$. The European Union estimates a wave energy cost of about $5 € / \mathrm{kWh}$.

\section{Conclusions}

Wave energy is not expensive to operate and maintain, no fuel is needed and no waste is produced. However, it depends on the intensity of the waves and needs a suitable site where waves are consistently strong. The infrastructure must be able to withstand very rough weather.

Wave power lies not in huge plants but in a combination of on-shore generation and near-shore generation (using a different technology) focused on meeting local or regional needs. If this system prove to be economically possible, only $0.1 \%$ of the renewable energy within the world's oceans could supply more than five times the global demand for energy,

The Pelamis Wave Energy Converter is a revolutionary concept resulting from many years of engineering development. It was the world's first commercial scale machine to generate electrical energy into the grid from offshore wave energy and the first to be used in commercial wave park projects. In Portugal, Pelamis System is now proving to be successful.

\section{Acknowledgement}

Thanks are due to the Electrical Engineering Department of the Faculty of Sciences and Technology of Nova University of Lisbon for the help in the preparation of this work. The author is also grateful to Centre for Technology and Systems (CTS) from Uninova for the financial support provided.

\section{References}

[1] Bent SØrenfen: “Renewable Energy”, Elsevier Academic Press, 2004 Edition.

[2] A.J.N.A. Sarmento, L.M.C. Gato, A.F. de O. Falcão, "Turbine-controlled wave energy absorption by oscillating-water-column devices". Ocean Engineering, vol. 17, p. 481-497, 1990.

[3] A.O. Falcão, P..P. Justino, “OWC wave energy converters with valve-constrained air flow”, Proceedings of the Second European Wave Power Conference, European Commission, EUR 16932 EN, 1995.

[4] A.F. de O. Falcão, P.A.P. Justino, "OWC Wave Energy Devices with Air-flow Control”. Ocean Engineering, vol. 26, p.1249-73. 1999.

[5] B. Weedy and B. Cory: "Electric Power Systems", Wiley, Fourth Edition, London 1998.

[6] Wikipedia: Web site on Power Waves 